\title{
Evaluation of Headspace Solid-Phase Microextraction Gas Chromatography-Mass Spectrometry for the Characterization of Volatile Organic Compounds from Melon (Cucumis melo L.) Flowers
}

\author{
Francisca Aliny Nunes Silva ${ }^{1}$ - Alexander Alves da Silva ${ }^{2} \cdot$ Nayanny de Sousa Fernandes ${ }^{3}$. \\ Tigressa Helena Soares Rodrigues ${ }^{4} \cdot$ Kirley Marques Canuto $^{1} \cdot$ Ronaldo Ferreira do Nascimento $^{5}$. \\ Edy Sousa de Brito ${ }^{1}$. Fernando Antonio Souza de Aragão ${ }^{1}$ Breno Magalhães Freitas ${ }^{3} \cdot$ Guilherme Julião Zocolo $^{1}$ (1)
}

Received: 27 November 2017 / Revised: 28 March 2018 / Accepted: 6 June 2018 / Published online: 18 June 2018

(c) Springer-Verlag GmbH Germany, part of Springer Nature 2018

\begin{abstract}
The secondary metabolism of plants plays a key role in plant-insect interactions. Among the various classes of metabolites produced, volatile organic compounds (VOCs) play important echophysiological roles, including the attraction of pollinators. This work aimed to develop a method to extract VOCs using headspace (HS) and solid-phase microextraction (SPME), which can be applied in future studies to contribute to the understanding of the role of VOCs in the pollination process. Therefore, a HS-SPME method combined with gas chromatography-mass spectrometry (GC-MS) was developed for the extraction and characterization of VOCs of melon flowers (Cucumis melo L.). The extraction was carried out with the fibers PDMS, DVB/ CAR/PDMS and CAR/PDMS for the times 15, 30, and $45 \mathrm{~min}$. Fifty compounds belonging to the following chemical classes were identified: terpenes, hydrocarbons, esters, ethers, ketones, aldehydes, and alcohols. CAR/PDMS fiber extracted the largest amount of compounds, and was more efficient for the extraction of volatile compounds with lower molecular weight, low boiling point and ideal for analytes in low concentration. Therefore, the evaluated method proved to be a promising tool for the analysis of VOCs of melon flowers, to be applied in new studies of the relationships between chemical composition and the processes of attraction of pollinators.
\end{abstract}

\section{Graphical Abstract}

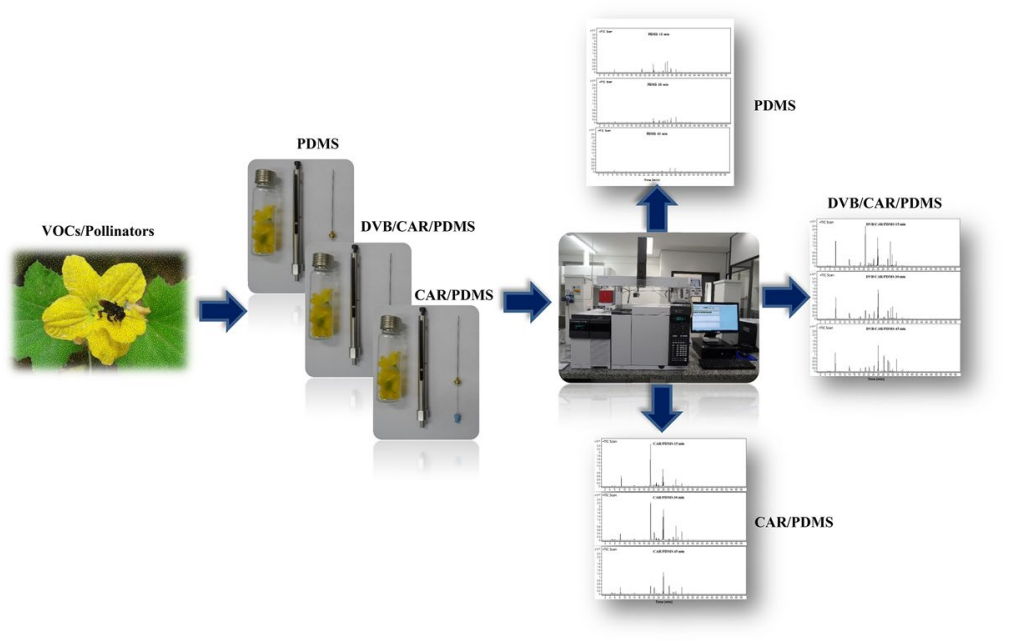

Keywords VOCs $\cdot$ Melon flower $\cdot$ Headspace $\cdot$ SPME $\cdot$ GC-MS

Extended author information available on the last page of the article 


\section{Introduction}

Volatile organic compounds (VOCs) emitted by terrestrial plants play a fundamental role in the interaction with biotic and abiotic environments. Released by plant tissues such as leaves, flowers and fruits, VOCs are classified as: alcohols, aldehydes, ketones, esters, ethers, hydrocarbons, terpenoids, phenylpropanoids/benzenoids and derivatives of fatty acids and amino acids [1,2]. The volatile compounds (VOCs) of plants have the function of attracting pollinators animals, and seed dispersers, assisting in reproduction. Of these VOCs, terpenes and esters are physiologically important and are present in floral aromas. Among the wild and cultivated plants that require animal pollination, bees are the main pollinators [3-7]. Because of this, bees are used in pollination of various agricultural crops, such as, the melon (Cucumis melo L. Cucurbitaceae) [7].

The melon, fruit from India and central regions of Africa and Asia, and currently cultivated in all tropical regions of the world, is totally dependent on pollination by bees, presenting productivity drops of up to $80 \%$ in the absence of these pollinators $[6,7]$. Thus, thousands of colonies of honey bee (Apis mellifera) are used every year in melon crops around the world. However, these bees seem to be more attracted to some varieties of melon than others and there is evidence that VOCs play a key role in attractiveness/ repulsiveness of floral visitors, whether pollinators or pests $[5,8]$. Furthermore the recognition that VOCs are important factors in fruit quality and have relevant economic impacts, volatile melon compounds have been extensively studied by several authors, in which more than 250 compounds were identified. However, most of these studies have concentrated on the aroma compounds of the fruit, by correlating with flavor and the physiological changes during various stages of treatment of the fruit, including: maturation, post-harvest, processing, and storage [9-11]. Therefore, there are no reports of the volatiles composition of melon flowers. Thus, research focusing on the VOCs emitted by agricultural crops such as melon may be of utmost importance for the development of new agricultural products, for the defense of the plant and for the identification of molecules responsible for attracting pollinators. Therefore, the development of new analytical tools, can allow a great advance in the understanding of the functions of the volatiles and their applications. In the qualitative and quantitative analysis of the VOCs, the solid-phase microextraction (SPME) technique stands out, which is based on the absorption and/or adsorption processes of the analytes, which can be followed by thermal desorption directly on the analytical instrument [12]. So, a simple and versatile technique in which the extraction and preconcentration of volatile and semi-volatile analytes can be carried out in a short time without the use of organic solvents [12]. Therefore, the goal of this work was to develop a method for extracting volatile compounds using solid-phase microextraction (SPME) to identify the volatile organic compounds of melon flowers.

\section{Experimental}

\section{Plant Material}

This study used male flowers of the accession of melon PI 183257 (Cucumis melo var. inodorus-originating from Saudi Arabia), cultivated from September to December 2014 in a greenhouse at Embrapa Tropical Agroindustry, Fortaleza, State of Ceará, Brazil.

\section{Extraction and Analysis}

\section{Sample Treatment}

Flowers of melon-were cut in the region of the peduncle, and with the aid of forceps, the flowers were placed in $20 \mathrm{~mL}$ glass bottles sealed with screw caps containing silicone/ PTFE septa (Supelco, Bellefonte, PA, USA). Three flowers of the same size and age were collected for each solid-phase microextraction fiber test (SPME).

\section{Headspace-SPME Extraction}

For headspace SPME extraction, we used a manual support of SPME fibers, with coatings of different polarities: CAR/ PDMS (carboxen/polydimethylsiloxane) $75 \mu \mathrm{m} 1 \mathrm{~cm}$, PDMS (polydimethylsiloxane) $100 \mu \mathrm{m} 1 \mathrm{~cm}, \mathrm{DVB} / \mathrm{CAR} / \mathrm{PDMS}$ (divinylbenzene/carboxen/polydimethylsiloxane) 50/30 $\mu \mathrm{m}$ $2 \mathrm{~cm}$ (Supelco, Bellefonte, PA, USA). Prior to the analyses, fibers were conditioned according to the temperature recommended by the manufacturer. For evaluation of the different types of fibers and the time of extraction, the vial containing the sample was preincubated at $35^{\circ} \mathrm{C}$ for $15 \mathrm{~min}$, after which the SPME fiber was exposed inside the vial of each sample (headspace) without stirring and under heating at $35^{\circ} \mathrm{C}$, where it was maintained at extraction times of 15,30 and $45 \mathrm{~min}$ [13]. After extraction of analytes, the fiber was removed from the flask and immediately inserted into the gas chromatograph injector (GC-MS) for $3 \mathrm{~min}$ for thermal desorption at $240{ }^{\circ} \mathrm{C}$. All evaluations were performed in duplicate. 


\section{Chromatographic Analysis}

\section{GC-MS Analysis}

Gas chromatography-mass spectrometry analysis was carried out on a gas chromatograph (7890B GC System Agilent Technologies Spain, SL, Madrid, Spain) coupled to a mass spectrometer equipped with a quadrupole analyzer (5977A MSD Agilent Technologies Spain, SL, Madrid, Spain). Chromatographic separation was performed using a DB5MS capillary column (Agilent J \& W GC Columns, Santa Clara, CA, USA) with $60 \mathrm{~m} \times 0.25 \mathrm{~mm}$ D.I $\times 0.25 \mu \mathrm{m}$ film thickness. The injector temperature was $240{ }^{\circ} \mathrm{C}$, injections were made in splitless mode. The carrier gas was helium (99.999\%) at a flow rate of $1 \mathrm{~mL} \mathrm{~min}-1$. The oven temperature program was $40{ }^{\circ} \mathrm{C}$ for $4 \mathrm{~min}$, then programmed to $80{ }^{\circ} \mathrm{C}$ at $2.5^{\circ} \mathrm{C} \mathrm{min}^{-1}$, and then increased to $110^{\circ} \mathrm{C}$ at $5^{\circ} \mathrm{C} \min ^{-1}$, and finally increased to $220^{\circ} \mathrm{C}$ at $10^{\circ} \mathrm{C} \min ^{-1}$, maintained for $23 \mathrm{~min}$. Mass spectra were obtained in the electron ionization mode (EI) at $7 \mathrm{eV}$ and in the mass range of 50-600 Da, using the software MassaHunter Workstation software-Qualitative Analysis version B.06.00 Agilent Technologies (City, Country). The transfer line and ionization source temperatures were 280 and $150{ }^{\circ} \mathrm{C}$, respectively. The results of the analyses were expressed in relative abundance. The compounds identification was performed by comparing the mass spectra acquired with the spectra of NIST 2.0 Library, 2012 (National Institute of Standards and Technology, Gaithersburg, Md, USA). The identification was also made by comparing the calculated linear retention index using a homologous series of C7-C30 n-alkanes (Supelco, 49451-U, Bellefonte, PA, USA) with the retention indices of the databases of NIST.

\section{Results and Discussion}

\section{Fiber Selection}

Three types of fiber coatings (PDMS, CAR/PDMS, DVB/ CAR/PDMS) were evaluated for their efficiency of extracting volatile compounds from flowers of melon. The performance of each fiber was determined based on the number of chromatographic peaks detected, in which the fibers with the best performances were CAR/PDMS and DVB/CAR/ PDMS, extracting 40 and 38 volatile compounds, respectively (Table 1).

It was possible to propose the identification of 50 volatile compounds belonging to the following classes of chemical compounds: alcohols (13), aldehydes (3), ketones (1), ethers (3), esters (9), hydrocarbons (2) and terpenes (20) (Table 1).
The PDMS fiber was more efficient for the extraction of compounds with higher molecular weight, considering that the DVB/CAR/PDMS and CAR/PDMS fibers extracted both intermediate and high molecular weight compounds (Table 1). This is due to the coating of the PDMS fiber is absorbent, which are formed by liquid polymers, in which the analytes are attracted to the coating phase mainly by polarity [14]. The extraction efficiency depends on the thickness of the liquid layer and the size of the analyte, so the adsorption of the analyte depends on the diffusion coefficient, and thus a high value of the diffusion coefficient of the analytes favors the analyte/fiber partition equilibrium. On the other hand, the polarity of the fiber may increase the attraction of the analytes, but it is the thickness of the coating that prevails in the analyte retention [12].

The heterogeneous fibers (bipolar)—DVB/CAR/PDMS and CAR/PDMS - are of adsorbent type coatings, formed by porous solids, in which the extraction is carried out by sorption of analytes in internal pores, in which the adsorption occurs by Van der Waals interactions or hydrogen bonds. In this type of coating, there are a limited number of adsorption sites, that is, for analytes at high concentrations, there is saturation of the surface available for adsorption and consequently competition between the analytes [12, 14].

The compounds 3-tujen-2-ol, 3-methoxymethoxy-1-propenyl-benzene, benzyl benzoate and sabinene transhydrate were extracted by the PDMS fiber (Table 1). Other 3 compounds (ethyl butyrate, methyl tiglate, ethyl tiglate) were extracted only by the DVB/CAR/PDMS fiber, while the CAR/PDMS fiber exclusively extracted 8 compounds: 2-ethylcyclobutanol, hotrienol, cis-1,3-diol-4-cyclopentene, 3-methyl-3-butenol, 5-methoxypentene, terpineol acetate, cis-oxide limonene and $\alpha$-fenchene, most of these compounds have intermediate molecular weight (Table 1). In addition, other 19 compounds were common to the three types of fiber evaluated, and the major compounds were benzyl alcohol, limonene and $\alpha$-terpineol. This can be attributed to the high selectivity of the three fibers to terpenes and alcohols (Table 1).

The results of fiber performance are presented in Table 2 (expressed in the absolute area values at 15, 30 and $45 \mathrm{~min}$ of extraction time).

In PDMS fiber at extraction times of 15, 30 and $45 \mathrm{~min}$, it was verified that the majority of the compounds reached equilibrium within $15 \mathrm{~min}$, where 25 compounds were extracted. As the extraction time increased, the number of extracted compounds decreased. In Table 2 , it is observed that the absolute area values of most compounds of lower molecular weight and/or smaller size decreases as the extraction time increases. There was also an increase in the absolute area of esters compounds with extension of the extraction time. In fact, this is because higher weight 
Table 1 Identification of volatile compounds from flowers of melon extracted by the fibers PDMS, DVB/CAR/PDMS, CAR/PDMS

\begin{tabular}{|c|c|c|c|c|c|c|c|c|}
\hline \multicolumn{2}{|c|}{ Volatile compounds } & \multirow{2}{*}{$\frac{\mathrm{tR}^{\mathrm{a}}(\min )}{4.66}$} & \multirow{2}{*}{$\begin{array}{l}\text { Identification } \\
\mathrm{MS}^{\mathrm{h}}\end{array}$} & \multirow{2}{*}{$\begin{array}{l}\mathrm{LRI}^{\mathrm{b}} \\
\mathrm{NC}\end{array}$} & \multirow{2}{*}{$\mathrm{LRI}^{\mathrm{c}}$} & \multirow{2}{*}{$\begin{array}{l}\text { PDMS }^{\mathrm{d}} \\
\text { R.Match \% } \\
-\end{array}$} & \multirow{2}{*}{$\begin{array}{l}\text { DVB/CAR/PDMS } \\
\text { R.Match } \%^{\mathrm{e}} \\
98\end{array}$} & \multirow{2}{*}{$\begin{array}{l}\text { CAR/PDMS } \\
\text { R.Match \% } \\
97\end{array}$} \\
\hline 1 & Acetone & & & & & & & \\
\hline 2 & 5-Methoxypentene & 4.78 & MS & $\mathrm{NC}$ & & - & - & 77 \\
\hline 3 & Methyl acetate & 4.98 & MS & $\mathrm{NC}$ & & - & 95 & 97 \\
\hline 4 & 2-Ethyl-cyclobutanol & 5.83 & MS & $\mathrm{NC}$ & & - & - & 86 \\
\hline 5 & 2-Methyl-3-buten-2-ol & 6.1 & MS & $\mathrm{NC}$ & & - & 87 & 88 \\
\hline 6 & cis-1,3-Diol-4-cyclopentene & 6.11 & MS & $\mathrm{NC}$ & & - & - & 65 \\
\hline 7 & Hotrienol & 6.15 & MS & $\mathrm{NC}$ & & - & - & 75 \\
\hline 8 & 1-Penten-3-ol & 7.79 & MS & $\mathrm{NC}$ & & - & 92 & 94 \\
\hline 9 & 3-Methyl-3-butenol & 9.54 & MS & $\mathrm{NC}$ & & - & - & 85 \\
\hline 10 & Pentanol & 9.66 & MS & $\mathrm{NC}$ & & - & 96 & 96 \\
\hline 11 & l-2-Methyl-1-butanol & 9.82 & MS & $\mathrm{NC}$ & & - & 93 & 88 \\
\hline 12 & Ethyl butyrate & 12.84 & MS & $\mathrm{NC}$ & & - & 90 & - \\
\hline 13 & 3-Hexenol & 15.91 & $\mathrm{MS}, \mathrm{IK}^{\mathrm{i}}$ & 849 & 845 & - & 94 & 94 \\
\hline 14 & Methyl tiglate & 16.51 & MS, IK & 871 & 875 & - & 89 & - \\
\hline 15 & Styrene & 17.99 & MS, IK & 890 & 890 & 88 & 91 & 91 \\
\hline 16 & $\alpha$-Thujene & 20.27 & MS, IK & 934 & 929 & - & 89 & 89 \\
\hline 17 & $\alpha$-Pinene & 20.67 & MS, IK & 941 & 937 & 92 & 96 & 95 \\
\hline 18 & Ethyl tiglate & 20.99 & MS, IK & 947 & 949 & - & 89 & - \\
\hline 19 & $\alpha$-Fenchene & 21.46 & MS, IK & 955 & 953 & - & - & 90 \\
\hline 20 & Camphene & 21.55 & MS, IK & 957 & 953 & - & 93 & 93 \\
\hline 21 & Benzaldehyde & 22.2 & MS, IK & 967 & 964 & 91 & 96 & 96 \\
\hline 22 & Sabinene & 22.94 & MS, IK & 980 & 975 & 90 & 93 & 92 \\
\hline 23 & $\beta$-Pinene & 23.13 & MS, IK & 983 & 979 & 88 & 92 & 91 \\
\hline 24 & $\beta$-Myrcene & 23.84 & MS, IK & 994 & 990 & 89 & 89 & 88 \\
\hline 25 & $\alpha$-Phellandrene & 24.55 & MS, IK & 1007 & 1004 & - & 86 & 84 \\
\hline 26 & $\alpha$-Terpinene & 25.14 & MS, IK & 1023 & 1017 & - & 89 & 81 \\
\hline 27 & $o$-Cymene & 25.54 & MS, IK & 1032 & 1026 & - & 92 & 92 \\
\hline 28 & Limonene & 25.71 & MS, IK & 1037 & 1031 & 93 & 94 & 95 \\
\hline 29 & Benzyl alcohol & 25.9 & MS, IK & 1041 & 1045 & 89 & 94 & 93 \\
\hline 30 & o-Ocimene & 26.53 & MS, IK & 1057 & 1052 & 87 & 89 & - \\
\hline 31 & $\gamma$-Terpinene & 27.01 & MS, IK & 1068 & 1062 & 78 & 89 & 80 \\
\hline 32 & Sabinene cis-hydrate & 27.34 & MS, IK & 1076 & 1071 & 86 & 81 & 83 \\
\hline 33 & Terpinolene & 28.13 & MS, IK & 1093 & 1092 & 92 & 93 & 79 \\
\hline 34 & Methyl benzoate & 28.35 & MS, IK & 1098 & 1092 & 93 & 94 & 94 \\
\hline 35 & Terpineol acetate & 28.46 & MS & 1101 & - & - & - & 78 \\
\hline 36 & Sabinene transhydrate & 28.47 & MS, IK & 1102 & 1097 & 82 & - & - \\
\hline 37 & cis-Limonene oxide & 29.57 & MS, IK & 1143 & 1145 & - & - & 84 \\
\hline 38 & 3-Tujen-2-ol & 29.9 & MS & 1155 & - & 79 & - & - \\
\hline 39 & Benzenepropanal & 30.35 & MS, IK & 1172 & 1163 & 86 & 86 & - \\
\hline 40 & Ethyl benzoate & 30.55 & MS, IK & 1179 & 1173 & 95 & 95 & 95 \\
\hline 41 & $\begin{array}{l}\text { cis-7a-Dimethylhexahydro-3a-2(3h)-benzofura- } \\
\text { none }\end{array}$ & 30.89 & MS & 1191 & - & - & 74 & 74 \\
\hline 42 & $\alpha$-Terpineol & 31.07 & MS, IK & 1197 & 1195 & 92 & 94 & 94 \\
\hline 43 & Methyl salicylate & 31.19 & MS, IK & 1201 & 1198 & 89 & 93 & 90 \\
\hline 44 & Verbenone & 31.57 & MS, IK & 1221 & 1218 & 91 & 93 & 92 \\
\hline 45 & Benzenepropanol & 31.93 & MS, IK & 1239 & 1231 & 95 & 96 & 95 \\
\hline 46 & Cinnamaldehyde & 32.8 & MS, IK & 1282 & 1273 & 92 & 91 & 93 \\
\hline 47 & Cinnamyl alcohol & 33.41 & MS, IK & 1314 & 1309 & 90 & 91 & 85 \\
\hline 48 & 3-Methoxymethoxy-1-propenyl-benzene & 33.67 & MS & 1330 & - & 76 & - & - \\
\hline
\end{tabular}


Table 1 (continued)

\begin{tabular}{|c|c|c|c|c|c|c|c|}
\hline Volatile compounds & $\mathrm{tR}^{\mathrm{a}}(\min )$ & Identification & $\mathrm{LRI}^{\mathrm{b}}$ & $\mathrm{LRI}^{\mathrm{c}}$ & $\begin{array}{l}\text { PDMS }^{\mathrm{d}} \\
\text { R.Match \% }\end{array}$ & $\begin{array}{l}\text { DVB/CAR/PDMS } \\
\text { R.Match } \%^{\mathrm{e}}\end{array}$ & $\begin{array}{l}\text { CAR/PDMS } \\
\text { R.Match } \%\end{array}$ \\
\hline 49 2,6,10-Trimethyl-dodecane & 35.74 & MS & 1446 & - & 91 & 90 & - \\
\hline 50 Benzyl benzoate & 40.28 & MS & 1794 & - & 90 & - & - \\
\hline
\end{tabular}

${ }^{a} \mathrm{tR}(\min )$ : retention time in minutes

${ }^{\mathrm{b}} \mathrm{LRI}$ : linear retention index experimental

${ }^{c}$ LRI: linear retention index in the literature

${ }^{\mathrm{d}}$ PDMS: polydimethylsiloxane-coated fibers $(100 \mu \mathrm{m})$

${ }^{\mathrm{e}} \mathrm{DVB} / \mathrm{CAR} / \mathrm{PDMS}$ : divinylbenzene-coated fibers $(50 / 30 \mu \mathrm{m})$

${ }^{\mathrm{f}} \mathrm{CAR} / \mathrm{PDMS}$ : carboxen/Polydimethylsiloxane-coated fibers $(75 \mu \mathrm{m})$

${ }^{g}$ R.Match \%: similarity to database of NIST 2.0, 2012 (National Institute of Standards and Technology, Gaithersburg, Md, EUA)

${ }^{\mathrm{h}}$ MS: comparison of mass spectra to database of NIST 2.0, 2012 (National Institute of Standards and Technology, Gaithersburg, Md, EUA)

iIK: Kovats index, according to the literature

and larger size analytes require longer time to migrate in the coating and, while the analytes with lower weight and smaller size move rapidly [12-14]. In DVB/CAR/PDMS fiber at the different extraction times, most of the extracted compounds reached equilibrium in the time of 30 and $45 \mathrm{~min}$, with the largest number of compounds extracted in 45 min, in which 32 compounds were extracted. This can be justified by the fact that the fiber is provided with three different types of coatings (DVB, CAR and PDMS), thus, of intermediate polarity, this coating enables the extraction of volatile and semi-volatile compounds containing 3 to 20 carbon atoms, covering a wide range of polarity $[13,14]$. The CAR/PDMS fiber favored the extraction of more volatile compounds in the time of $30 \mathrm{~min}$, where 36 volatile to semi-volatile compounds were extracted. Actually, using CAR/PDMS, it was possible to extract a wide range of compounds, volatile and semi-volatiles, with intermediate weight and size, due to the presence of different types of pores (micro-, meso- and macropores) [15]. CAR/PDMS porous fiber extracted the greatest amount of compounds, followed by DVB/CAR/PDMS fiber, while the homogeneous PDMS fiber presented a lower number of extracted compounds. Thereby it was possible to develop a simplified and robust method for the sampling of VOCs from melon flowers, in which it was possible to identify different chemical classes of volatile compounds in this study. Additionally, the VOCs identified in this work have been reported in other studies, whose majority has focused on the compounds aroma, because they relate to the flavor and/or changes that occur during maturation the fruit, such as: alcohols, aldehydes and esters have been shown to be important for the aroma of the melon fruit. Analysis of VOCs of the melon fruit has already been carried out by gas chromatography-olfactometry ( $\mathrm{GC}-\mathrm{O})$ and gas chromatography-mass spectrometry (GC-MS), in which, verified that the esters can contribute with a fruity flavor, sweet, and melon-like aroma. There is esters were related as active odor compounds by gas chromatography-olfactometry and contribute to the aroma of ripe melons [9-11].

Overall, neither of the previous studies has focused particularly on the volatiles from melon flowers. Thereby, the extreme importance and necessity of additional studies is verified, which aimed only at volatiles of from melon flower in an attempt to correlate them with the defense of the plant and for the identification of molecules responsible for attracting of pollinators.

\section{Conclusions}

In this study, it was possible to evaluate the performance of different coatings of SPME fibers to extract and identify the largest number of volatiles of melon flowers. The CAR/ PDMS fiber allowed the extraction of volatile compounds with lower weight, low boiling point and analytes at low concentrations. Studies of volatile melon compounds have already been described in other studies, with the majority interested in fruit aromas. Nowadays, there have been no studies focused on the volatile organic compounds of melon flowers. Therefore, the method stands out for presenting results associated with the technique HS-SPME-GC-MS proved to be an appropriate tool for the qualitative analysis of volatile compounds from melon flowers. This work provides important information for the realization of future studies involving the generation of knowledge regarding the VOC profile that will allow the understanding of the main functions of these substances and their implications in the field of Chemical Ecology. 


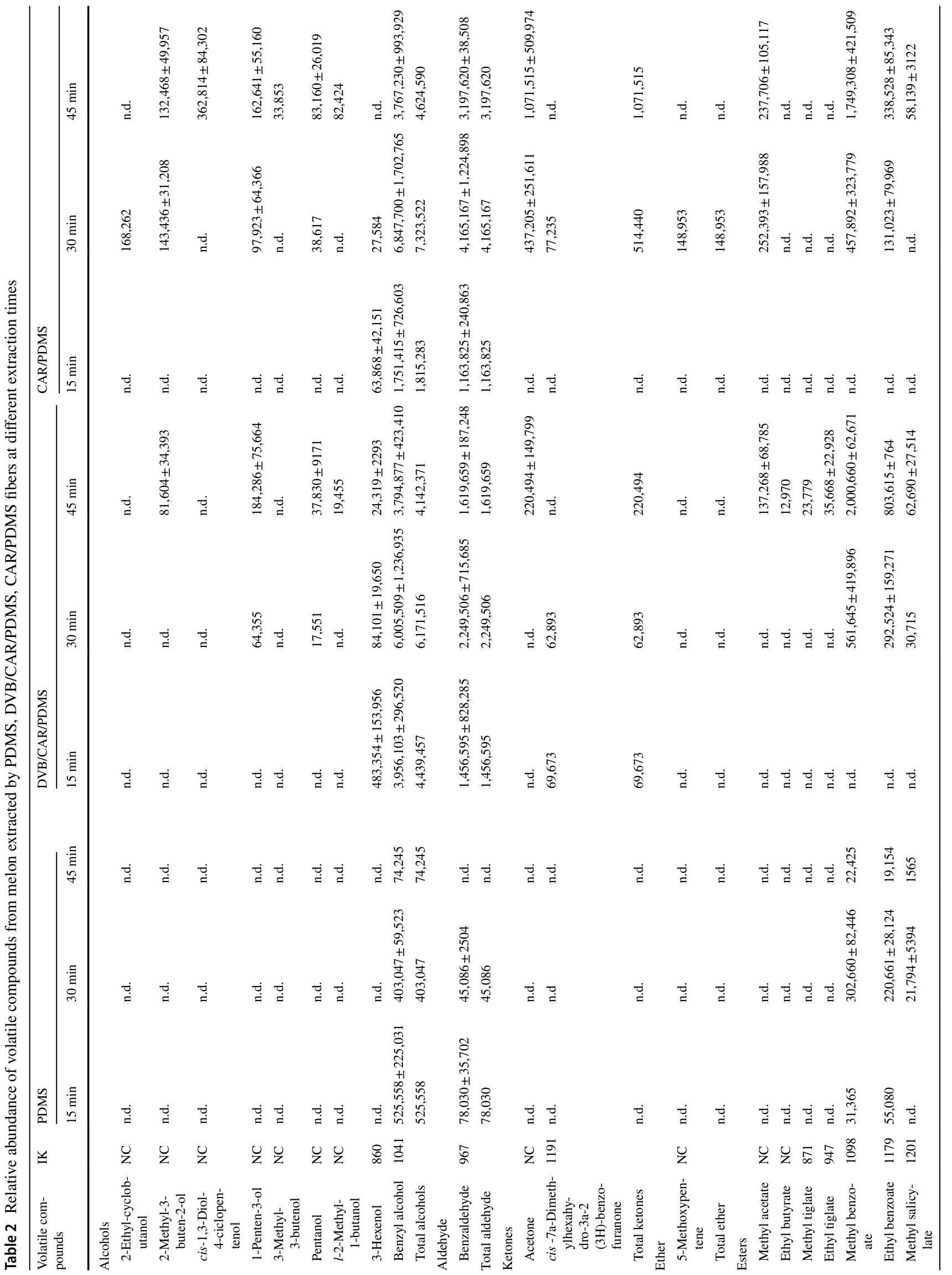




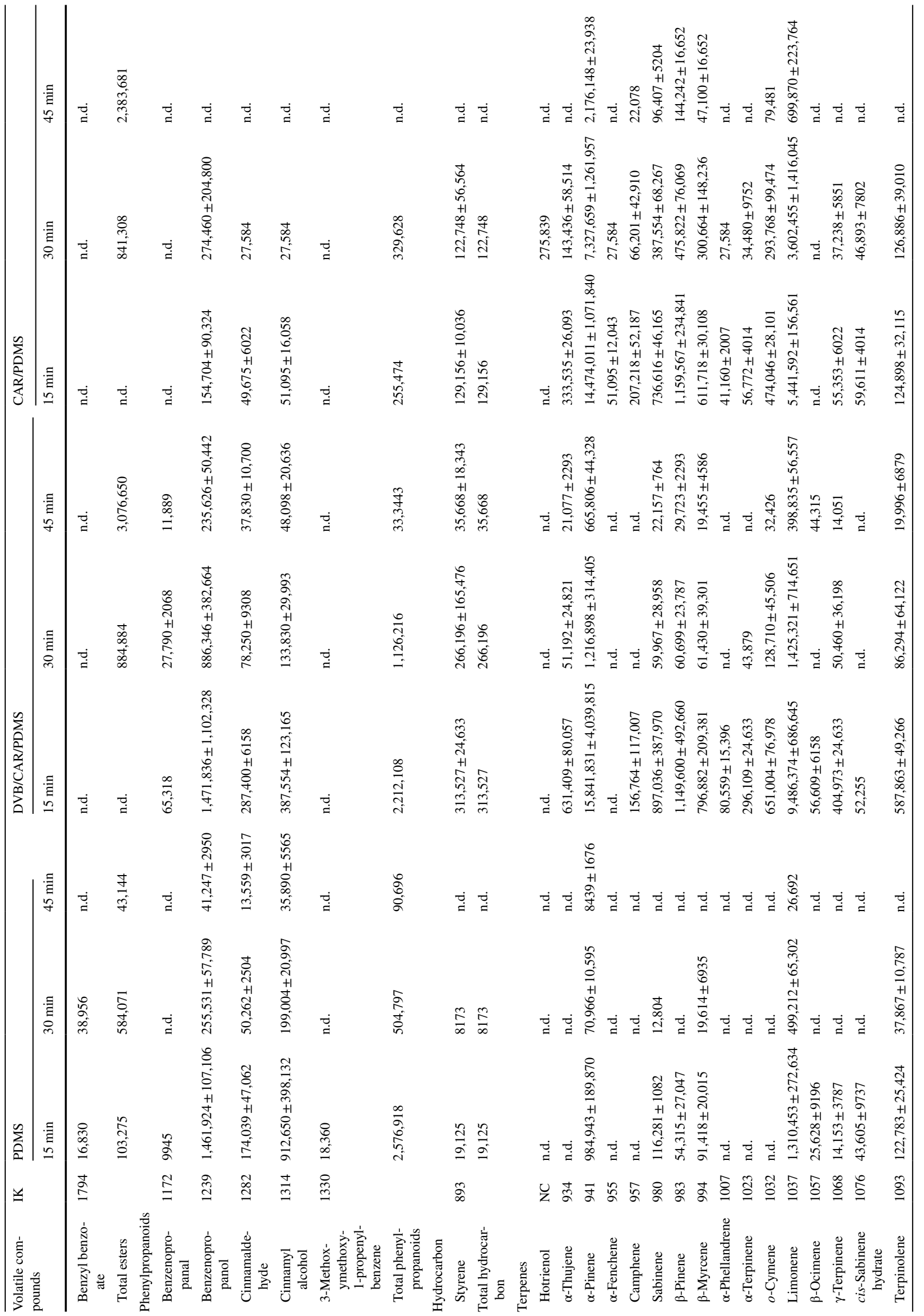




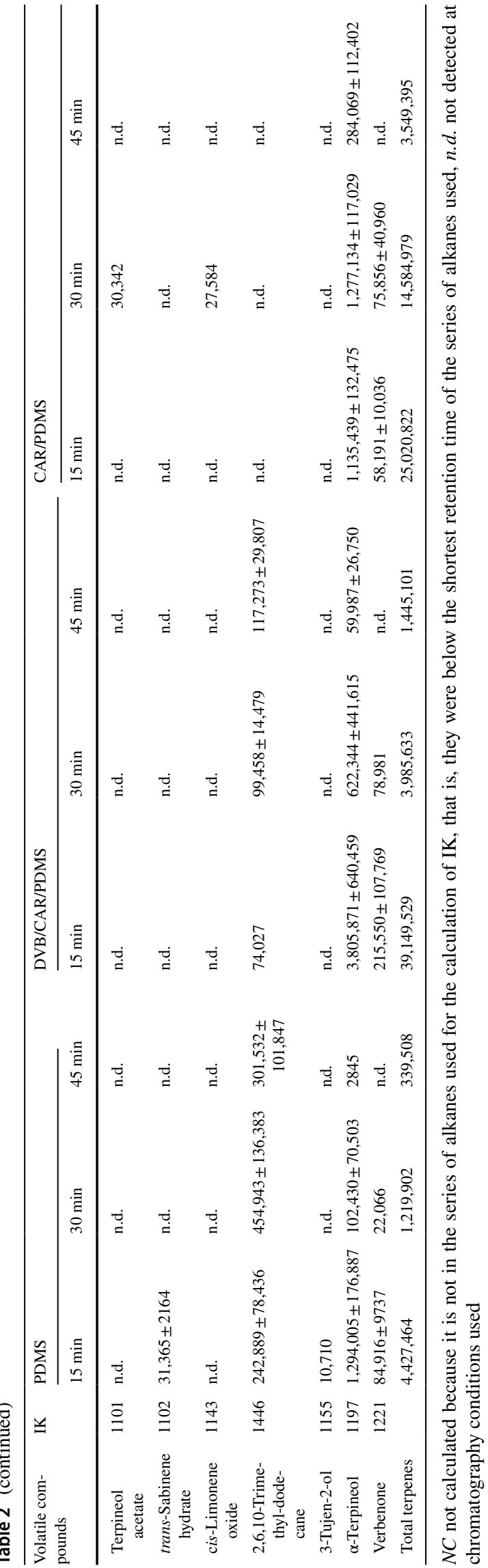

Acknowledgements The authors would like to thank the Ministry of Agriculture, Livestock and Food Supply (SEG 03.14.04.002.00.00) in Brazil for the support of this study. Breno M. Freitas acknowledges CNPq, Brasilia - Brazil for a Productivity in Research sponsorship (\#305126/2013-0).

Funding This research was supported by Research Grants (SEG 03.14.04.002.00.00) from the Ministry of Agriculture, Livestock and Food Supply (SEG 03.14.04.002.00.00) in Brazil.

\section{Compliance with Ethical Standards}

Conflict of interest The author declares that he has no conflict of interest.

Ethical approval This article does not contain any studies with human participants or animals performed by the authors.

\section{References}

1. Dudareva N, Pichersky E (2008) Metabolic engineering of plant volatiles. Curr Opin Biotechnol 19:181-189

2. Kesselmeier J, Staudt M (1999) Biogenic volatile organic compounds (VOC): an overview on emission, physiology and ecology. J Atmos Chem 33:23-88

3. Pichersky E, Gershenzon J (2002) The formation and function of plant volatiles: perfumes for pollinator attraction and defense. Curr Opin Plant Biol 5:237-243

4. Pichersky E, Dudareva N (2007) Scent engineering: toward the goal of controlling how flowers smell. Trends Biotechnol 25:105-110

5. Farré-Armengol G, Filella I, Llusia J, Peñuelas J (2013) Floral volatile organic compounds: between attraction and deterrence of visitors under global change. Perspect Plant Ecol Evol Syst 15:56-67

6. Giannini TC, Cordeiro GD, Freitas BM et al (2015) The dependence of crops for pollinators and the economic value of pollination in Brazil. J Econ Entomol 108:849-857

7. Potts SG, Imperatriz-Fonseca VL, Ngo HT, Biesmeijer JC, Breeze TD, Dicks LV, Garibaldi LA, Hill R, Settele J, Vanbergen AJ, Aizen MA, Cunningham SA, Eardley C, Freitas BM, Gallai N, Kevan PG, Kovács-Hostyánszki A, Kwapong PK, Li J, Li X, Martins DJ, Nates-Parra G, Pettis JS, Rader R, Viana BF. IPBES (2016) Summary for policymakers of the assessment report of the Intergovernmental Science-Policy Platform on Biodiversity and Ecosystem Services on pollinators, pollination and food production. Bonn, Germany

8. Klatt BK, Burmeister C, Westphal C et al (2013) Flower volatiles, crop varieties and bee responses. PLoS ONE 8:e72724

9. Jordán MJ, Shaw PE, Goodner KL (2001) Volatile components in aqueous essence and fresh fruit of Cucumis melo cv. Athena (Muskmelon) by GC-MS and GC-O. J Agric Food Chem 49:5929-5933. https://doi.org/10.1021/jf010954o

10. Aubert C, Bourger N (2004) Investigation of volatiles in charentais cantaloupe melons (Cucumis melo Var. cantalupensis). characterization of aroma constituents in some cultivars. J Agric Food Chem 52:4522-4528. https://doi.org/10.1021/jf049777s

11. Allwood JW, Cheung W, Xu Y et al (2014) Metabolomics in melon: a new opportunity for aroma analysis. Phytochemistry 99:61-72. https://doi.org/10.1016/j.phytochem.2013.12.010

12. Pawliszyn J (2012) Development of SPME devices and coatings. In: Handbook of solid phase microextraction, 1st edn. Elsevier, Oxford 
13. Lorenzo JM (2014) Influence of the type of fiber coating and extraction time on foal dry-cured loin volatile compounds extracted by solid-phase microextraction (SPME). Meat Sci 96:179-186. https://doi.org/10.1016/j.meatsci.2013.06.017

14. Risticevic S, Lord H, Górecki T et al (2010) Protocol for solidphase microextraction method development. Nat Protoc 5:122139. https://doi.org/10.1038/nprot.2009.179
15. Garcia-Esteban M, Ansorena D, Astiasarán I, Ruiz J (2004) Study of the effect of different fiber coatings and extraction conditions on dry cured ham volatile compounds extracted by solidphase microextraction (SPME). Talanta 64:458-466. https://doi. org/10.1016/j.talanta.2004.03.007

\section{Affiliations}

Francisca Aliny Nunes Silva ${ }^{1} \cdot$ Alexander Alves da Silva ${ }^{2} \cdot$ Nayanny de Sousa Fernandes $^{3}$. Tigressa Helena Soares Rodrigues ${ }^{4} \cdot$ Kirley Marques Canuto $^{1} \cdot$ Ronaldo Ferreira do Nascimento $^{5}$. Edy Sousa de Brito ${ }^{1}$. Fernando Antonio Souza de Aragão ${ }^{1} \cdot$ Breno Magalhães Freitas $^{3} \cdot$ Guilherme Julião Zocolo $^{1}(\mathbb{C}$

Guilherme Julião Zocolo guilherme.zocolo@embrapa.br

1 Laboratório Multiusuário de Química de Produtos NaturaisEmbrapa Agroindústria Tropical, Rua Dra. Sara Mesquita, 2270-Pici, Fortaleza, CE 60020-181, Brazil

2 Institute of Chemistry, São Paulo State University (Unesp), Rua Prof. Francisco Degni, 55, Bairro: Quitandinha, Araraquara, SP 14800-060, Brazil
3 Laboratório de Abelhas, Departamento de Zootecnia-CCA , Universidade Federal do Ceará, Campus Universitário do Pici, Bloco 814, Fortaleza, CE 60356-000, Brazil

4 Curso de Química, Centro de Ciências Exatas e Tecnologia, Universidade Estadual Vale do Acaraú, Avenida da Universidade 850, Sobral, CE 62040-370, Brazil

5 Departamento de Química Analítica e Físico-Química, Centro de Ciências, Universidade Federal do Ceará, Fortaleza, CE 60455-760, Brazil 